\title{
Association of Serum Bilirubin with Stroke Severity and Clinical Outcomes
}

\author{
Tian Xu, Jintao Zhang, Tan Xu, Wenqing Liu, Yan Kong, Yonghong Zhang
}

\begin{abstract}
Objective: The aim of the study is to explore the association of serum bilirubin levels with admission severity and short term clinical outcomes among acute ischemic stroke patients. Methods: Data were collected from 2361 acute ischemic stroke patients in four hospitals of Shangdong Province during January 2006 and December 2008. National Institutes of Health Stroke Scale (NIHSS) was used to assess admission and discharge severity. NIHSS $\geq 10$ at discharge or in-hospital death was defined as short-term clinical outcomes. Logistic regression and trend test were used to examine the association of serum bilirubin levels with admission severity and short term clinical outcomes. Results: Serum bilirubin levels were significantly and positively associated with admission severity (P for trend $<0.05$ ). The age-sex adjusted odds ratios (95\% confidential intervals) of NIHSS $\geq 10$ associated with the second, third and fourth quartile of total bilirubin/direct bilirubin were $1.245(0.873,1.777) / 1.276(0.895,1.818), 1.484(1.048,2.102) / 1.628(1.158,2.289)$ and $2.869(2.076,3.966) / 2.765(1.996,3.828)$, respectively, compared with the lowest quartile; the multivariate adjusted odds ratios of NIHSS $\geq 10$ associated with the second, third and fourth quartile of total bilirubin/direct bilirubin were $1.088(0.711,1.665) / 1.436(0.94$, $2.193), 1.328(0.877,2.011) / 1.647(1.092,2.485)$ and $2.336(1.579,3.458) / 3.079(2.049,4.623)$, respectively, compared with the lowest quartile. However, no association between serum bilirubin levels and short-term clinical outcomes was observed in our study. Conclusion: Serum bilirubin levels were associated with initial stroke severity closely. Nevertheless, there is no significant relationship between serum bilirubin levels and short-term clinical outcomes among acute ischemic stroke patients.
\end{abstract}

RÉSUMÉ: Association du taux de bilirubine sérique avec la sévérité de l'accident vasculaire cérébral et l'issue clinique. Objectif : Le but de l'étude était d'examiner l'association entre le niveau de bilirubine sérique et la sévérité clinique au moment de l'arrivée à l'hôpital ainsi que l'issue clinique à court terme chez des patients atteints d'un accident vasculaire cérébral ischémique aigu (AVCIA). Méthode : Les données de 2361 patients atteints d'un AVCIA ont été recueillies dans quatre hôpitaux de la province de Shangdong de janvier 2006 à décembre 2008. L'échelle National Institutes of Health Stroke Scale (NIHSS) a été utilisée pour évaluer la sévérité de l'AVC au moment de l'entrée et du congé hospitalier. L'issue clinique à court terme était définie comme étant un score $\geq 10$ à la NIHSS au moment du congé hospitalier ou le décès en milieu hospitalier. L'analyse de régression logistique et l'analyse de tendance ont été utilisées pour examiner l'association entre le niveau de bilirubine sérique et la sévérité au moment de l'entrée à l'hôpital ainsi que l'issue clinique à court terme. Résultats : Le taux de bilirubine sérique était significativement et positivement associé à la sévérité au moment de l'arrivée à l'hôpital (tendance $\mathrm{P}<0,05)$. Le rapport de cotes ajusté pour le sexe (intervalle de confiance à $95 \%$ ) d'un score $\geq 10$ à la NIHSS associé au deuxième, troisième et quatrième quartiles de bilirubine totale/bilirubine directe étaient 1,245 $(0,873$ à 1,777)/1,276 (0,895 à 1,818), 1,484 (1,048 à $2,102) / 1,628(1,158$ à 2,289) et 2,869 (2,076 à 3,066)/2,765 (1,996 à 3,828) respectivement par rapport au quartile le plus bas. Les rapports de cotes avec ajustement multivarié d'un score $\geq 10$ à la NIHSS associé au deuxième, troisième et quatrième quartile de bilirubine totale/bilirubine directe étaient $1.088(0,711$ à 1,665$) / 1,436(0,94$ à 2,193), 1,328 (0,877 à 2,011)/1,647 (1,092 à 2,485) et 2,336 (1,579 à 3,458)/3,079 $(2,049$ à 4,623) respectivement par rapport au quartile le plus bas. Cependant, nous n'avons pas observé d'association entre le niveau de bilirubine sérique et l'issue clinique à court terme dans notre étude. Conclusion : Le niveau de bilirubine sérique était étroitement associé à la sévérité initiale de l'AVC. Néanmoins, il n'existe pas de relation significative entre le niveau de bilirubine sérique et l'issue clinique à court terme chez les patients atteints d'un AVCIA.

Can J Neurol Sci. 2013; 40: 80-84

Stroke now ranks second to ischemic heart disease as a cause of death and is a leading cause of long-term disability worldwide ${ }^{1}$. Over two-thirds of stroke deaths worldwide are in developing countries ${ }^{2}$. In China, stroke is an enormous health issue as the second most common cause of death, accounting for nearly $20 \%$ of all deaths in both rural and urban settings ${ }^{3}$. Although the incidence and proportion of hemorrhagic stroke is higher in the Chinese population than in Western populations, ischemic stroke is still the dominant subtype of stroke in China ${ }^{4}$.

Bilirubin, the end product of heme catabolism in mammals, is generally regarded as a potentially cytotoxic, lipid-soluble waste product that needs to be excreted ${ }^{5}$. However, recent data indicated that bilirubin exhibits potent antioxidant properties with substantial positive clinical consequences ${ }^{6}$. Some studies suggested that bilirubin plays an important role in the progress of various diseases associated with oxidative stress including ischemic stroke ${ }^{7-10}$.

There are currently few data on the relationship between serum bilirubin levels and acute ischemic stroke in the Chinese population. In the present study, we aimed to examine the

From the Department of Epidemiology (TiX, TaX, YZ), School of Public Health, Medical College of Soochow University, Suzhou, Jiangsu Province; Department of Neurology (JZ, WL, YK), The 88th Hospital of PLA, Tai'an, Shandong Province, China.

Received March 28, 2012. Final Revisions Submitted July 5, 2012 Correspondence to: Yonghong Zhang, Department of Epidemiology, School of Public Health, Medical College of Soochow University, 199 Renai Road, Industrial Park District, Suzhou, Jiangsu Province, China, 215123. Email: yhzhang@suda.edu.cn. 
association of serum bilirubin levels with admission severity and short term clinical outcomes among acute ischemic stroke patients.

\section{METHODS}

\section{Study participants}

This cross-sectional and follow-up study was conducted between 1 January 2006 and 31 December 2008 in four hospitals of Shandong Province, China. Two thousand, six hundred and seventy five acute ischemic patients, confirmed by a computed tomography (CT) scan or magnetic resonance imaging (MRI), were investigated. Three hundred and fourteen patients were excluded for missing data of bilirubin or other covariates. Stroke patients who were not admitted into the four hospitals including those who died outside of hospitals were not included in this analysis. This study was approved by Soochow University School of Public Health Ethics Committee.

\section{Data collection}

Baseline data were collected within the first 24 hours of hospital admission by in-person interview with patients or their family members (if patients were not able to communicate). Data on demographic characteristics, life-style risk factors, medical history, clinical laboratory tests, and imaging data (CT and MRI) were obtained using a standard questionnaire administered by trained staff. Cigarette smokers were defined as having smoked at least one cigarette per day for one year or more. Data on the amount and type of alcohol consumed during the past year were collected. Alcohol consumption was defined as consuming one or more alcoholic drinks per day during the last year. Blood pressure measurements were taken within 30 minutes of admission and in the first 72 hours (one measurement every eight hours) after admission while the study participants were in the supine position using a standard mercury sphygmomanometer according to a standard protoco ${ }^{11}$.

Blood specimens were collected from all subjects within 24 hours of hospital admissionafter fasting (at least eight hours). Total bilirubin (Tbil) was measured by the 2,5-dichlorophenyldiazonium (DPD) method $^{12}$ and direct bilirubin (Dbil) was measured by the method of Jendrassik et al ${ }^{13}$. Modified hexokinase enzymatic method was applied to test plasma glucose levels ${ }^{14}$. Total cholesterol, high-density lipoprotein (HDL)cholesterol, and triglycerides were analyzed enzymatically on a Beckman Synchron CX5 Delta Clinical System (Beckman Coulter, Inc., Fullerton, California, USA) using commercial reagents ${ }^{15}$. Low-density lipoprotein (LDL)-cholesterol levels were calculated using Friedewald equation ${ }^{16}$.

A comprehensive clinical evaluation with National Institutes of Health stroke scale (NIHSS) was conducted at admission and discharge. If a patient died in the hospital, a study staff member recorded the death on the event form and obtained the death certificate. In admission, NIHSS $\geq 10$ was considered as higher severity (primary outcome) in the cross-sectional analysis. NIHSS $\geq 10$ at discharge or in-hospital death was defined as short term clinical outcomes (secondary outcome) in the follow-up analysis ${ }^{17}$.

\section{Statistical analysis}

The unadjusted means and standard deviations (SD) of normally-distributed continuous variables, mean ranks of ordinal variables and prevalence of categorical variables were calculated for baseline characteristics according to different admission severity and discharge status. Analysis of variance was used to calculate $\mathrm{P}$ values for difference in the means of continuous variables. Rank sum test was used to calculate $P$ values for difference in mean ranks of ordinal variables. $\chi^{2}$ test or Fisher exact test was used to calculate $\mathrm{P}$ values for difference in the prevalence of categorical variables. We used dichotomous variable as an outcome based on NIHSS $\geq 10$ /death or NIHSS $<10$ and used Tbil and Dbil as exposures, which were quartile in the logistic regression model adjusted for age, sex, and other confounders and potential confounders in order to get unbiased parameter estimates. We also carefully examined collinearity between exposure and other confounders in the model and found there is no severe collinearity since all variance inflation factors (VIFs) between bilirubin and confounders were under 2.5. We did linear trend tests using Tbil and Dbil as continuous variables in the logistic regression. All $\mathrm{P}$ values were two-tailed and a significance level of 0.05 was used. Statistical analysis was conducted using SAS statistical software (version 9.13; SAS Institute Inc, Cary, North Carolina, USA).

\section{RESULTS}

A total of 2361 acute ischemic stroke patients were included in our analysis. Table 1 presents the demographic and clinical characteristics by admission NIHSS. Those with higher admission NIHSS were more likely to be male and older, have higher alcohol consumption, systolic blood pressure (BP) levels, plasma glucose, serum Tbil, serum Dbil and lower triglycerides, have higher rates of histories of stroke, atrial fibrillation and rheumatic heart disease. Statistically significant differences were found in the mean of age, alcohol consumption, blood pressure, plasma glucose, serum Tbil, serum Dbil, triglycerides and the proportion of men, in-hospital complications, histories of diabetes and atrial fibrillation among three groups divided by discharge status (Table 2).

Age and sex-adjusted and multivariable-adjusted odds ratios of admission severity by the quartiles of Tbil and Dbil are presented in Table 3. The age and sex-adjusted odds ratios of severity were significantly higher in the third and top quartiles of Tbil and Dbil. The multivariable-adjusted odds ratios of severity were significantly higher in the top quartile of Tbil and the third and top quartiles of Dbil. There was a dose-response relationship between Tbil/Dbil levels and admission severity (all $\mathrm{P}$ values for linear trend were less than 0.05). However, serum Tbil/Dbil levels were not significantly associated with short clinical outcomes including discharge NIHSS $\geq 10$ or death inhospital after confounding factors adjusted.

\section{Discussion}

The primary findings of this study are that elevated levels of serum Tbil and Dbil are associated with increased odds of admission severity in acute ischemic stroke patients. In contrast, both serum levels of Tbil and Dbil are poor prognostic factors for acute ischemic stroke in a short term. 
Table 1: Characteristics of 2361 ischemic stroke patients according to admission NIHSS

\begin{tabular}{|c|c|c|c|}
\hline variables & $\begin{array}{l}\text { admission } \\
\text { NIHSS } \geq 10\end{array}$ & $\begin{array}{l}\text { admission } \\
\text { NIHSS }<10\end{array}$ & $\mathrm{p}$ values \\
\hline No. of participants & 347 & 2014 & \\
\hline Men, no. $(\%)$ & $200(57.6)$ & $1293(64.2)$ & 0.019 \\
\hline Age, mean (SD) (years) & $65.418(11.52)$ & $63.745(11.792)$ & 0.0144 \\
\hline Cigarette smoking, no. $(\%)$ & $93(26.8)$ & $529(26.3)$ & 0.834 \\
\hline Alcohol consumption (mean rank) & 6.93 & 1.15 & $0.028^{*}$ \\
\hline Admission systolic pressure mean $(\mathrm{SD})(\mathrm{mmHg})$ & $148(26)$ & $145(21)$ & 0.0252 \\
\hline Admission diastolic pressure mean $(\mathrm{SD})(\mathrm{mmHg})$ & $89(15)$ & $88(13)$ & 0.1356 \\
\hline plasma glucose mean $(\mathrm{SD})(\mathrm{mmol} / \mathrm{L})$ & $7.321(3.74)$ & $6.333(2.594)$ & $<0.0001$ \\
\hline Total cholesterol mean $(\mathrm{SD})(\mathrm{mmol} / \mathrm{L})$ & $4.93(1.231)$ & $5.026(1.167)$ & 0.1396 \\
\hline Triglycerides mean $(\mathrm{SD})(\mathrm{mmol} / \mathrm{L})$ & $1.3715(0.8594)$ & $1.5693(1.1454)$ & $<0.0001$ \\
\hline HDL cholesterol mean(SD) (mmol/l) & $1.2789(0.3736)$ & $1.2629(0.3483)$ & 0.486 \\
\hline $\begin{array}{l}\text { LDL cholesterol mean(SD) }(\mathrm{mmol} / \mathrm{l}) \\
\text { serum level of Tbil mean(SD) }(\mathrm{umol} / \mathrm{l})\end{array}$ & $\begin{array}{c}2.921(0.9174) \\
17.97(9.559)\end{array}$ & $\begin{array}{l}3.0096(0.872) \\
14.385(6.926)\end{array}$ & $\begin{array}{c}0.1223 \\
<0.0001\end{array}$ \\
\hline serum level of Dbil mean(SD) (umol/l) & $4.616(3.583)$ & $3.343(2.424)$ & $<0.0001$ \\
\hline History of hypertension no. (\%) & $204(58.8)$ & $1254(62.3)$ & 0.219 \\
\hline History of diabetes no. $(\%)$ & $48(13.8)$ & $297(14.7)$ & 0.656 \\
\hline History of coronary heart disease, no. (\%) & $55(15.9)$ & $318(15.8)$ & 0.977 \\
\hline History of atrial fibrillation, no. (\%) & $33(9.5)$ & $41(2.0)$ & 0.000 \\
\hline History of stroke, no. (\%) & $128(36.9)$ & $616(30.6)$ & 0.02 \\
\hline History of rheumatic heart disease, no. (\%) & $12(3.5)$ & $10(0.5)$ & 0.000 \\
\hline history of dyslipidemia no. (\%) & $130(37.5)$ & $766(38)$ & 0.84 \\
\hline Family history of stroke no. (\%) & $27(7.8)$ & $128(6.4)$ & 0.322 \\
\hline Family history of hypertension no. (\%) & $22(6.3)$ & $129(6.4)$ & 0.963 \\
\hline Family history of diabetes no. (\%) & $3(0.9)$ & $14(0.7)$ & 0.999 \\
\hline
\end{tabular}

* We categorize alcohol consumption as four ordinal levels (high: 4, medium: 3, low: 2, none: 1).

$\mathrm{SD}=$ standard deviation; Tbil=total bilirubin; Dbil=direct bilirubin; HDL=high-density lipoprotein; LDL=low-density lipoprotein

Table 2: Characteristics of 2361 ischemic stroke patients according to discharge status

\begin{tabular}{|c|c|c|c|c|}
\hline variables & $\begin{array}{c}\text { Discharge } \\
\text { NIHSS }<10\end{array}$ & $\begin{array}{c}\text { discharge } \\
\text { NIHSS } \geq 10\end{array}$ & death & $\mathrm{p}$ values \\
\hline No. of participants & 2192 & 152 & 17 & \\
\hline Age, mean (SD) (years) & $63.86(11.77)$ & $65.05(11.53)$ & $71.94(11.24)$ & 0.0096 \\
\hline Cigarette smoking, no. (\%) & $579(26.4)$ & $40(26.3)$ & $3(17.6)$ & 0.716 \\
\hline Alcohol consumption (mean rank) & 1.06 & 15.77 & 180.28 & $0.009^{* *}$ \\
\hline In-hospital complication, no. (\%) & $30(1.4)$ & $5(3.3)$ & $4(23.5)$ & $0.000^{*}$ \\
\hline plasma glucose mean(SD) $(\mathrm{mmol} / \mathrm{L})$ & $6.40(2.73)$ & $7.33(3.36)$ & $9.25(4.75)$ & $<0.0001$ \\
\hline \multirow{2}{*}{$\begin{array}{l}\text { Total cholesterol mean }(\mathrm{SD})(\mathrm{mmol} / \mathrm{L}) \\
\text { Triglycerides mean }(\mathrm{SD})(\mathrm{mmol} / \mathrm{L})\end{array}$} & $5.01(1.158)$ & $5.022(1.428)$ & $5.214(1.497)$ & 0.7292 \\
\hline & $1.515(1.095)$ & $1.326(0.894)$ & $1.466(1.609)$ & 0.0469 \\
\hline HDL cholesterol mean(SD) $(\mathrm{mmol} / \mathrm{l})$ & $1.283(0.365)$ & $1.289(0.354)$ & $1.282(0.247)$ & 0.9866 \\
\hline LDL cholesterol mean(SD) $(\mathrm{mmol} / \mathrm{l})$ & $2.975(0.855)$ & $3.047(1.035)$ & $3.237(1.236)$ & 0.3241 \\
\hline History of coronary heart disease, no. (\%) & $345(15.7)$ & $25(16.4)$ & $3(17.6)$ & 0.952 \\
\hline History of atrial fibrillation, no. (\%) & $58(2.6)$ & $14(9.2)$ & $2(11.8)$ & $0.000^{*}$ \\
\hline History of stroke no. $(\%)$ & $691(31.5)$ & $48(31.6)$ & $5(29.4)$ & 0.983 \\
\hline History of rheumatic heart disease, no. (\%) & $19(0.9)$ & $3(2.0)$ & $0(0.00)$ & $0.29^{*}$ \\
\hline history of dyslipidemia no. $(\%)$ & $836(38.1)$ & $52(34.2)$ & $8(47.1)$ & 0.464 \\
\hline Family history of stroke, n (\%) & $147(6.7)$ & $7(4.6)$ & $1(5.9)$ & 0.596 \\
\hline Family history of hypertension, $\mathrm{n}(\%)$ & $144(6.6)$ & $7(4.6)$ & $0(0.00)$ & $0.54^{*}$ \\
\hline Family history of diabetes, $\mathrm{n}(\%)$ & $15(0.7)$ & $1(0.7)$ & $1(5.9)$ & $0.134^{*}$ \\
\hline
\end{tabular}

* Fisher exact test; ** We categorize alcohol consumption as four ordinal levels (high: 4, median: 3, low: 2, none: 1). $\mathrm{SD}=$ standard deviation 
Table 3: Odds ratios and 95\% confidence intervals (CI) of severity associated with total bilirubin and direct bilirubin among acute ischemic stroke patients

\begin{tabular}{|c|c|c|c|c|}
\hline \multirow[b]{2}{*}{ variables } & \multicolumn{2}{|l|}{ Age-sex adjusted } & \multicolumn{2}{|l|}{ Multivariable-adjusted } \\
\hline & odds ratio $95 \%(\mathrm{CI})$ & $\begin{array}{l}\mathrm{p} \text { value for linear } \\
\text { trend }^{*}\end{array}$ & odds ratio $95 \%(\mathrm{CI})$ & $\begin{array}{l}\mathrm{p} \text { value for } \\
\text { linear trend }\end{array}$ \\
\hline \multicolumn{5}{|l|}{ Total bilirubin } \\
\hline Q1 (1.0-10.0) & $1.0(\mathrm{ref})$ & \multirow{4}{*}{0.0003} & $1.0(\mathrm{ref})$ & \\
\hline Q2 (10.1-13.4) & $1.245(0.873,1.777)$ & & $1.088(0.711,1.665)$ & \\
\hline Q3 (13.5-17.9) & $1.484(1.048,2.102)$ & & $1.328(0.877,2.011)$ & 0.0032 \\
\hline Q4 (18.0-88.0) & $2.869(2.076,3.966)$ & & $2.336(1.579,3.458)$ & \\
\hline \multicolumn{5}{|l|}{ Direct bilirubin } \\
\hline Q1 (0.4-2.0) & $1.0(\mathrm{ref})$ & \multirow{4}{*}{0.0012} & $1.0(\mathrm{ref})$ & \multirow{4}{*}{0.0126} \\
\hline Q2 (2.1-2.9) & $1.276(0.895,1.818)$ & & $1.436(0.94,2.193)$ & \\
\hline Q3 (3.0-4.1) & $1.628(1.158,2.289)$ & & $1.647(1.092,2.485)$ & \\
\hline Q4 (4.2-37) & $2.765(1.996,3.828)$ & & $3.079(2.049,4.623)$ & \\
\hline
\end{tabular}

Primary outcome: In admission, NIHSS $\geq 10$ was considered higher severity. Multivariable adjustment included age, sex, alcohol consumption, cigarette smoking, blood levels of glucose and lipids, admission SBP and DBP, blood urea nitrogen, serum creatinine, sodium, hematocrit, history of stroke, hypertension, diabetes, coronary heart disease, rheumatic heart disease, and atrial fibrillation, family history of stroke, hypertension and diabetes. $\mathrm{SBP}=$ systolic blood pressure, $\mathrm{DBP}=$ diastolic blood pressure. * p values for linear trends were estimated by using bilirubin as continuous variables in multiple logistic models.

Our findings are consistent with other studies that have reported a significant association between elevated bilirubin levels and greater stroke severity instead of patients' outcome $^{18,19}$. However, in these studies, only Dbil levels showed a significant association with stroke severity on admission whereas Tbil did not. A possible reason for this discrepancy is that several studies have suggested Dbil level is more sensitive among individuals with general medical conditions ${ }^{20-22}$. However, the sample size of our study is more than three fold the previous study, so that a relationship between serum Tbil levels and stroke severity is more likely to be discovered.

The generation of free radicals leading to oxidative stress is one of the mechanisms involved in brain damage induced by ischemia $^{23,24}$. Bilirubin, which, for many years, was thought to have no physiological function other than that of a waste product of heme catabolism, has been proved a potent antioxidant ${ }^{5,6}$. Dohi et al suggested that serum bilirubin might serve as a useful marker of oxidative stress in hemorrhagic stroke patients and high levels of bilirubin in patients with neurotrauma reflect its pathophysiological role in free radical scavenging 25 . Our results also indicated that the production of bilirubin in serum could be attributable to systemic oxidative stresses caused by vascular and brain damage, which could occur after stroke via heme oxygenases pathway activation ${ }^{26}$. Therefore, further study is warranted to investigate the relationship between serum bilirubin and oxidative stress and to confirm that the concentration of serum bilirubin may reflect intensity of oxidative stress, which may be closely associated with degree of stroke severity in our population.

A study including 453 stroke patients indicated that increment in bilirubin level was associated with reduced odds of an adverse stroke outcome. A possible explanation for this inconsistency is that admission severity was not chosen as an adjusted variable in multivariable model in this study ${ }^{27}$. As a matter of fact, admission severity was considered as a strong confounding factor influencing prognosis among stroke patients ${ }^{28}$, especially in our study which focused on short-term clinical outcomes.

This is the largest study in a Chinese population to examine the association of serum bilirubin levels with stroke admission severity and short-term clinical outcomes. The study data were collected with rigid quality control and important covariate variables were measured and controlled in the analysis. However, two limitations of this study should be mentioned. Firstly, association between serum bilirubin levels and admission severity was analyzed in a cross-sectional study. Therefore, a causal relationship between them could not be established. Secondly, the follow-up period of our study is relatively short, which prevented an evaluation of the long-term effects of serum bilirubin levels on acute ischemic stroke outcomes. Although serum bilirubin level may be used as a biomarker in predicting severity of stroke in our study, future research comparing bilirubin levels among stroke patients, healthy people, and other neurological disorders are warranted in Chinese population.

\section{Conclusion}

In summary, our study found that serum levels of bilirubin were significantly and positively associated with admission NIHSS $\geq 10$. A significant association was not observed between serum bilirubin levels and death or NIHSS $\geq 10$ at discharge. 


\section{ACKNOWLEDGEMENTS}

This study was supported by National Natural Science Foundation of China (Grant No. 30972531) and a Project of the Priority Academic Program Development of Jiangsu Higher Education Institutions.

Tian $\mathrm{Xu}$ and Jintao Zhang contributed equally to this work.

\section{REFERENCES}

1. WHO. The top 10 causes of death. Geneva, Switzerland: World Health Organization. 2008.

2. Feigin VL. Stroke epidemiology in the developing world. Lancet. 2005 Jun 25-Jul 1;365(9478):2160-1.

3. Heeley E, Anderson CS, Huang Y, et al. Role of health insurance in averting economic hardship in families after acute stroke in China. Stroke. 2009 Jun;40(6):2149-56.

4. Zhang LF, Yang J, Hong Z, et al. Proportion of different subtypes of stroke in China. Stroke. 2003 Sep;34(9):2091-6.

5. Stocker R, Yamamoto Y, McDonagh AF, Glazer AN, Ames BN. Bilirubin is an antioxidant of possible physiological importance. Science. 1987 Feb 27;235(4792):1043-6.

6. Vitek L. Impact of serum bilirubin on human diseases. Pediatrics. 2005 May;115(5):1411-2.

7. Oveson BC, Iwase $\mathrm{T}$, Hackett SF, et al. Constituents of bile, bilirubin and TUDCA, protect against oxidative stress-induced retinal degeneration. J Neurochem. 2011 Jan;116(1):144-53.

8. Liu Y, Zhu B, Wang X, et al. Bilirubin as a potent antioxidant suppresses experimental autoimmune encephalomyelitis: implications for the role of oxidative stress in the development of multiple sclerosis. J Neuroimmunol. 2003 Jun;139(1-2): 27-35.

9. Clark JE, Foresti R, Green CJ, Motterlini R. Dynamics of haem oxygenase- 1 expression and bilirubin production in cellular protection against oxidative stress. Biochem J. 2000 Jun 15;348 Pt 3:615-9.

10. Giral P, Ratziu V, Couvert P, et al. Plasma bilirubin and gammaglutamyltransferase activity are inversely related in dyslipidemic patients with metabolic syndrome: relevance to oxidative stress. Atherosclerosis. 2010 Jun;210(2):607-13.

11. Perloff D, Grim C, Flack J, et al. Human blood pressure determination by sphygmomanometry. Circulation. 1993 Nov; 88(5 Pt 1):2460-70.

12. Bhutani VK, Gourley GR, Adler S, Kreamer B, Dalin C, Johnson LH. Noninvasive measurement of total serum bilirubin in a multiracial predischarge newborn population to assess the risk of severe hyperbilirubinemia. Pediatrics. 2000 Aug;106(2):E17.

13. Morozova VT. [On a method of bilirubin determination (according to Jendrassik, Cleghorn and Grof)]. Lab Delo. 1965;10:588-91.

14. Sitzmann FC, Eschler P. [Enzymatic determination of blood glucose with a modified hexokinase method]. Med Klin. 1970 Jun $12 ; 65(24): 1178-83$.
15. Allain CC, Poon LS, Chan CS, Richmond W, Fu PC. Enzymatic determination of total serum cholesterol. Clin Chem. 1974 Apr; 20(4):470-5.

16. Friedewald WT, Levy RI, Fredrickson DS. Estimation of the concentration of low-density lipoprotein cholesterol in plasma, without use of the preparative ultracentrifuge. Clin Chem. 1972 Jun;18(6):499-502.

17. Khatri P, Hill MD, Palesch YY, et al. Methodology of the Interventional Management of Stroke III Trial. Int J Stroke. 2008 May;3(2):130-7.

18. Pineda S, Bang OY, Saver JL, et al. Association of serum bilirubin with ischemic stroke outcomes. J Stroke Cerebrovasc Dis. 2008 May-Jun;17(3):147-52.

19. Kurzepa J, Bielewicz J, Stelmasiak Z, Bartosik-Psujek H. Serum bilirubin and uric acid levels as the bad prognostic factors in the ischemic stroke. Int J Neurosci. 2009;119(12):2243-9.

20. Shiomi S, Habu D, Kuroki T, Ishida S, Tatsumi N. Clinical usefulness of conjugated bilirubin levels in patients with acute liver diseases. J Gastroenterol. 1999 Feb;34(1):88-93.

21. Reinhartz O, Farrar DJ, Hershon JH, Avery GJ, Jr., Haeusslein EA, Hill JD. Importance of preoperative liver function as a predictor of survival in patients supported with Thoratec ventricular assist devices as a bridge to transplantation. J Thorac Cardiovasc Surg. 1998 Oct:116(4):633-40.

22. Li B, Wang Z, Fang JJ, Xu CY, Chen WX. Evaluation of prognostic markers in severe drug-induced liver disease. World $\mathrm{J}$ Gastroenterol. 2007 Jan 28;13(4):628-32.

23. Ozkul A, Akyol A, Yenisey C, Arpaci E, Kiylioglu N, Tataroglu C. Oxidative stress in acute ischemic stroke. J Clin Neurosci. 2007 Nov;14(11):1062-6.

24. El Kossi MM, Zakhary MM. Oxidative stress in the context of acute cerebrovascular stroke. Stroke. 2000 Aug;31(8):1889-92.

25. Dohi K, Satoh K, Ohtaki H, et al. Elevated plasma levels of bilirubin in patients with neurotrauma reflect its pathophysiological role in free radical scavenging. In Vivo. 2005 SepOct;19(5):855-60.

26. Dohi K, Mochizuki Y, Satoh K, et al. Transient elevation of serum bilirubin (a heme oxygenase-1 metabolite) level in hemorrhagic stroke: bilirubin is a marker of oxidant stress. Acta Neurochir Suppl. 2003;86:247-9

27. Perlstein TS, Pande RL, Creager MA, Weuve J, Beckman JA. Serum total bilirubin level, prevalent stroke, and stroke outcomes: NHANES 1999-2004. Am J Med. 2008 Sep;121(9): 781-8 e1

28. Adams HP, Jr., Davis PH, Leira EC, et al. Baseline NIH Stroke Scale score strongly predicts outcome after stroke: A report of the Trial of Org 10172 in Acute Stroke Treatment (TOAST). Neurology. 1999 Jul 13;53(1):126-31. 